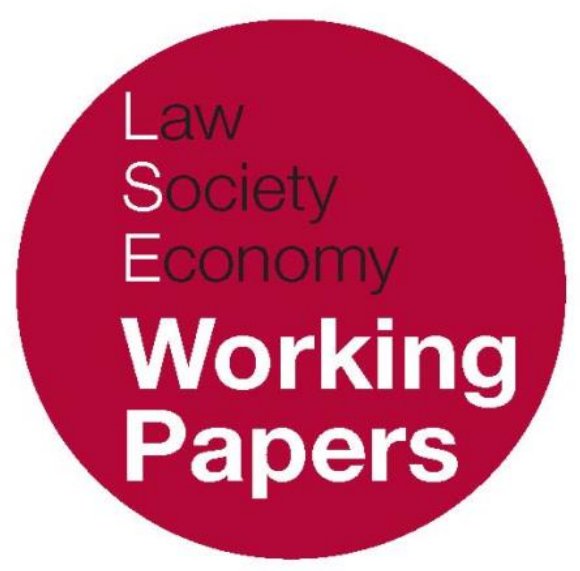

\title{
Legal Malingering: A Vortex of Uncertainty
}

\author{
Jill Peay
}

LSE Law, Society and Economy Working Papers 10/2019

London School of Economics and Political Science

Law Department

This paper can be downloaded without charge from LSE Law, Society and Economy Working Papers at: www.lse.ac.uk/collections/law/wps/wps.htm and the Social Sciences Research Network electronic library at: http://ssrn.com/abstract $=3406572$.

(C) Jill Peay. Users may download and/or print one copy to facilitate their private study or for non-commercial research. Users may not engage in further distribution of this material or use it for any profit-making activities or any other form of commercial gain. 


\title{
Legal Malingering: A Vortex of Uncertainty
}

\author{
Jill Peay*
}

\begin{abstract}
The assertion that an alleged offender is either pretending to be mentally disordered or exaggerating the extent of their disorder is an under-examined subject. This is curious since, if successful, the individual can avoid punishment altogether or mitigate its impact where greater state intervention would otherwise be justified. This paper explores the potential for such legal malingering and examines some cases where it may have occurred, but concludes that the fear of legal malingering may be more powerful than the reality of its occurrence.

It also observes, paradoxically, that the legal system is more at fault in failing to spot those whose impaired capacities should protect them from the full rigour of the criminal law; and that mental disorder is most likely overestimated as a cause of offending, but undervalued as a mitigating factor. The implications for issues of trust between the courts, clinical professionals, the public and the media are multi-faceted, and problematic. In this context, the paper serves largely to ask a series of questions about the implications of these issues; and the complex interplay between criminal capacity, legal responsibility, and criminal culpability.
\end{abstract}

* Professor of Law, London School of Economics and Political Science. E-mail j.peay@lse.ac.uk. I am very grateful to Genevra Richardson for her most helpful comments on an early draft of this paper. 
The evaluation of what went on in a person's mind while committing a crime will, despite technical innovations, in the end continue to rely on personal evaluations and interpretations. ${ }^{1}$

The view that courts should require something more is founded not on legal principle, but on policy - more particularly, on a collection of concerns regarding claims for mental injury ... founded upon dubious perceptions of, and postures towards, psychiatry and mental illness in general: that mental illness is "subjective" or otherwise easily feigned or exaggerated. ${ }^{2}$

It would be trite to suggest that we live in an age of uncertainty, but the law's business is, in part, about resolving uncertainties. Feigning mental disorder, ${ }^{3}$ and the fear that claimants may be either feigning or exaggerating their symptoms, has a long history in the civil field where tort law has grappled with what previously was known as 'nervous shock'. ${ }^{4}$ In the area of crime and mental disorder those uncertainties have been subject to less scrutiny. Indeed, it is curious that arguments over the validity of potential awards of damages should have attracted greater attention than those over attributed liability for offending. This paper accordingly concerns the vexed issue of legal malingering as one small aspect of the 'mental disorder and crime' terrain. Legal malingering, or the fear of legal malingering, is taken here to mean the assertion that an offender is either pretending to be mentally disordered or exaggerating their degree of disorder when involved in court processes.

Forensic psychiatrists are frequently the vehicle for assisting the courts in dealing with these fraught issues; but this is a task rife with ethical difficulties for them and accordingly one undertaken cautiously by the profession. ${ }^{5}$ Clinical malingering per se, without legal involvement, is not uncommon; and it can manifest itself as a distinct disorder, as for example in cases of Munchausen's syndrome 6 or Munchausen by Proxy Syndrome. ${ }^{7}$ This is not the subject of this paper. It is, however, testament to the inherent difficulties which patients with factitious disorders pose to clinicians; ${ }^{8}$ but it serves also as a counterpoint to the

${ }^{1}$ Melle I (2013) 'The Breivik case and what psychiatrists can learn from it' World Psychiatry 12(1): 16-21 at 20.

2 Saadati v. Moorhead, [2017] 1 SCR 543, 2017 SCC 28 (CanLII) at 21.

${ }^{3}$ Mental disorder is being used here in accordance with the definition under s.1(2) Mental Health Act 1983; that is 'mental disorder means any disorder or disability of the mind'.

4 See, for example, Mulheron R (2012) 'Rewriting the Requirement for a "Recognized Psychiatric Injury" in Negligence Claims' Oxford Journal of Legal Studies 32(1): 77-122; Teff H (2009) Causing Psychiatric and Emotional Harm: Reshaping the Boundaries of Legal Liability Oxford: Hart.

${ }^{5}$ Buchanan A and Zonana H (2009) 'Mental disorder as the cause of a crime' IJLP 32: 142-146.

${ }^{6}$ Asher R (1951) 'Munchausen's syndrome' Lancet I: 339-341.

${ }^{7}$ Levin A and Sheridan M (Eds) (1995) Munchausen Syndrome by Proxy: issues in diagnosis and treatment New York: Lexington Books.

${ }^{8} \mathrm{~A}$ factitious disorder is one where the patient takes on the sick role for attention or sympathy and it is regarded as pathological; malingering is where this is done for gain, and is not a disorder per se. Symptom exaggeration for the purposes of gain straddles the two. 
criminal cases. In Munchausen's pathological individuals are seeking positive attention; in the criminal context, they are seeking to avoid or mitigate a punitive response. Pathology may be present in some individuals, but in others it is an issue of frank manipulation of the system. It has also been noted that those with Munchausen by Proxy Syndrome can deliberately seek out perverse relationships with susceptible, caring professionals who in turn unknowingly draw others into a web of deception motivated by a desire to help. ${ }^{9}$ Drawing the line between disorder and deception can be acutely problematic.

Adding the component of 'mental' into an underlying disorder further complicates matters. In neurological disorders, which might be thought of as straddling the somatic/psychiatric divide, the role of exaggeration has been studied, but is phenomenally hard to assess. ${ }^{10}$ What is clear is that little has been written on the subject of mental disorder, malingering and the criminal process. The importance of the topic derives not only from its obvious potential to corrupt criminal processes, but the attribution of malingering can also play a role in underestimating the true impact of mental disorder. Such fears of mistaken or over-diagnosis thus have a part to play. It is often said that fear of crime is more harmful than crime itself; ${ }^{11}$ equally, fear of malingering might be as toxic as malingering per se.

Adding another level of complexity, the extended chronology of these cases introduces further difficulties. Thus, it is possible for an offender-patient retrospectively to claim that he or she had been malingering; with clinicians subsequently asserting that the disordered offender-patient is now masking symptoms that would otherwise be evident. All of these examples point to the difficulty that psychiatric diagnosis is more vulnerable to the vagaries of patientclinician interactions than some other aspects of medical diagnosis.

Finally, the paper is cognizant of the stigma associated with mental disorders and its implications. Both the denial of disorder and the assertion of it should be assessed in the context that an individual's narrative of what has had, or is happening to them, is vulnerable to active and/or unrecognised self-deception. Well-established parallel difficulties arise where an individual genuinely believes that they are physically disordered, but the root cause of that disorder actually lies in the realm of psychological or psychiatric expertise. Psychosomatic disorders in

\footnotetext{
9 See, for example, Wood H, Brown J and Wood P (2001) 'Differing approaches to the identification of Munchausen by proxy syndrome (MBPS): a case of professional training or role of experiential exposure' Journal of Clinical Forensic Medicine 8: 140-150 at 141-2.

${ }^{10}$ A survey of clinical neuropsychologists in the US involving 1,341 criminal cases reported a rate of $19 \%$ for probable malingering or symptom exaggeration: Mittenberg W, Patton C, Canyock E and Condit D (2002) 'Base rates of malingering and symptom exaggeration' Journal of Clinical and Experimental Neuropsychology 24(8): 1094-1102. A repeat of the survey in Australia, also involving neuropsychologists with a smaller sample of 108 criminal cases reported a base rate of $17 \%$ for symptom exaggeration or probable symptom exaggeration: Sullivan K, Lange R and Dawes S (2007) 'Methods of detecting malingering and estimated symptom exaggeration base rates in Australia' Journal of Forensic Neuropsychology 4(4): 49-70.

${ }^{11}$ For a brief review see https://en.wikipedia.org/wiki/Fear_of_crime.
} 
conventional medicine have a much larger role to play than is routinely credited. ${ }^{12}$ All of this creates uncertainty.

\section{THE CONTEXT OF LEGAL MALINGERING}

There are numerous contexts in which legal malingering, or the fear of it, can arise. They include those, for example, where there is a desire to avoid a reckoning with the punitive aspects of the criminal justice system. One such example would be through use of the unfitness to plead provisions. If successful an unfitness plea can lead to an acquittal, a discharge or to a therapeutic intervention, potentially on a compulsory basis in a psychiatric hospital. But it cannot result in a conviction, so conventional punishment cannot be a consequence. Another context for legal malingering is where an alleged offender argues that their mental disorder can account, in whole or in part, for their criminal behaviour. This could preclude a punitive response (via a verdict of not guilty by reason of insanity), or alleviate its punitive impact by arguing that an offender was not, or was not wholly responsible for their actions (through the use of a plea to diminished responsibility manslaughter on a charge of murder). Here mental disorder may be present and relevant; present and not relevant; or not present at all. Juries and judges will be the final arbiters. Mental disorder can also be cited with respect to a plea in mitigation after conviction. Again, mental disorder may be present but not highly relevant as a mitigating factor, or present and relevant, where the sentencer takes a prospective (rehabilitative) view with respect to the mental disorder. Had a retrospective (punitive) approach been adopted this would require some weighing of the mitigation deriving from the mental disorder with respect to that punitive response. Or mental disorder may not be present at all. Establishing certainty in any of these situations is thus a complex task, not aided at all by suggestions that alleged offenders may be malingering. Suffice it to say at this stage, the real issues concern not whether a disorder is absent or present, since true malingering in the field of mental disorder will be rare given the broad definitions of mental disorder. Indeed, true malingering should be relatively easy to spot. ${ }^{13}$ However, assessing the role and degree of disorder; and the extent to which there may be exaggeration

\footnotetext{
12 O'Sullivan S (2018) Is it all in your head? True stories of imaginary illness New York: Other Press. The controversy surrounding the cause of chronic fatigue syndrome also illustrates the strength of feeling around such issues: see https://www.dailymail.co.uk/health/article-6810393/Top-chronic-fatigueresearcher-QUITS-online-trolls-hostile.html and https://www.s4me.info/threads/michael-sharpe-onradio-4-today-tom-feilden-bbc-18th-march-2019.8632/page-3.

${ }^{13}$ Hence the apocryphal 'How many legs has a horse?' test. More advanced tests, for example the TOMM (test of memory malingering) have been shown to have high specificity and sensitivity for memory malingering. They are accordingly useful both in compensation assessments for traumatic brain injury and potentially in cases where an accused claims no memory for a particular incident. See http://criminal-justice.iresearchnet.com/forensic-psychology/test-of-memory-malingering-tomm/.
} 
on the part of the patient or uncertainty by the clinician is much more difficult. It is thus primarily an issue of trust; that is both trust by the courts in clinical professionals; and trust by the public in the capacity of the courts to determine these issues correctly. ${ }^{14}$ Yet trust in experts has become a vulnerable asset; its intangibility too easily trumped by powerful emotions which can, as the antivaccination movement has illustrated, result in profound dangers to health. ${ }^{15}$

To summarise, legal malingering is associated with the fear that individuals who are not mentally disordered are exploiting a legal protection or allowance. This legal protection is offered to ensure fairness between those who can adhere to the law's tenets, but choose not to, and those who cannot sufficiently adhere so as to be the legitimate subject of full punishment. Or, in the case of unfitness to plead, who should not be subject to a process that might result in their conviction, because the process itself could not be undertaken fairly. In all these contexts, the law is allegedly worried about 'being taken for a ride'.

\section{THE VORTEX OF UNCERTAINTY}

This paper is organised around an ad hoc series of cases and studies emanating out from a legal core focussing on malingering per se. It extends out through widening circles concerning fear of malingering, then a discussion of the vulnerability of assessment methods, through to an examination of the much wider problematic context in which these issues are set. This also includes the paradoxical questions relating to whether the focus is inappropriately located. The paper acknowledges from the start that this is not the most satisfactory of approaches, but since the reported cases are relatively rare, it has been written in the spirit of a preliminary approach, rather than the definitive article.

\section{A. The CORE OF LEGAL MALINGERING}

First, it should be stressed that malingering in civil contexts is not uncommon. ${ }^{16}$ One of the most widely known examples concerns claims for whiplash injuries arising out of minor car accidents in order to obtain compensation from insurance companies. The vast majority of these fraudulent insurance cases are settled out-

\footnotetext{
14 See, for a fascinating study of the erosion of trust in experts, Davies W (2018) Nervous States: How feeling took over the world London: Jonathan Cape.

15 For a brief history see https://www.historyofvaccines.org/content/articles/history-anti-vaccinationmovements; and for the recent measles controversy https://www.verywellhealth.com/the-mmrvaccination-autism-controversy-260556 and https://www.theguardian.com/commentisfree/2019/apr/27/vaccines-mmr-fears-anti-vaxxers. 16 https://www.theguardian.com/money/blog/2017/apr/29/whiplash-injury-claims-accident-mythneurosurgeon-speaks-out. Such dishonest behaviour is not without its criminal consequences if the deception is uncovered; see https://www.telegraph.co.uk/news/2019/04/08/woman-tried-claim-2mnhs-sent-prison-pictures-show-daughters/. Notably, this case also concerned symptom exaggeration rather than complete fabrication.
} 
of-court and claimants never have their dishonesty challenged, but some cases have resulted in prosecution. ${ }^{17}$ Whilst these cases do not self-evidently involve mental disorder, they are noted here briefly to support the assertions that people will dissemble when there is a gain to be made; that medical, legal and insurance personnel are not immune to getting caught up in this; that people can experience neck and back pains even when whiplash has been characterised as a myth; ${ }^{18}$ and that the soft tissue injuries associated with the less serious forms of whiplash are notoriously hard to diagnose. As Suzanne O'Sullivan notes, both malingering and factitious disorders are rare; and easy to spot: 'The behaviour of those patients is often different from conversion-disorder patients. Innocent or not, patients aware of their own deceit are evasive'. ${ }^{19}$ Yet in these whiplash cases the opportunities for 'spotting' are problematic; claimants are rarely challenged head-on and insurance companies have managed the necessary costs in the most efficient way available.

Pretending to have a disorder or exaggerating its effects where an offender is caught 'red-handed' is much more unusual. One recent case of feigned unfitness to plead is that of George Stephenson. Stephenson was convicted of 14 counts of rape on a girl, and on a charge of perverting the course of justice. He was sentenced to 26 years and four months' imprisonment. Prior to this outcome, he had convinced two psychiatrists that he was unfit to plead because of cognitive impairment with an 'oscar-winning performance' aided by his wife. The deception, which had in essence entailed his making unintelligible noises when interviewed, only came to light through a subsequent covert police operation. The case illustrates well how difficult assessing someone can be where an alleged offender feigns an inability to communicate in the context of pre-existing disorders. ${ }^{20}$

Another kind of illustration arises out of the case of Ian Brady, and in particular, his 2013 Tribunal hearing. ${ }^{21}$ The history of this case is both complex and notorious. Ian Brady was initially convicted in 1966 of three counts of murder and given life sentences of imprisonment. The offences were committed together with Myra Hindley, and the two became known as 'the moors murderers'. Brady spent many years in prison, but in November 1985 he was transferred to Ashworth Hospital as suffering from 'personality disorder of the psychopathic

\footnotetext{
17 https://www.lawgazette.co.uk/news/12-month-sentence-for-utterly-false-whiplashclaim/5057591.article; https://www.insurancetimes.co.uk/pair-sentenced-for-fraudulentwhiplash-claim-against-admiral/1414367.article.

18 https://www.irishtimes.com/opinion/onus-on-medical-profession-to-stop-supporting-mythof-whiplash-1.3058290.

${ }^{19}$ See footnote 12 above at 155. Malingerers make their claims for personal gain; those with factitious disorders have a 'mental disorder' in which the individual consciously reports symptoms to obtain sympathy or special attention; conversion disorders involve a form of somatization, in which mental symptoms like stress are converted into physical symptoms. The resulting physical disorders will accordingly have no obvious physical cause.

20 https://www.theguardian.com/uk-news/2019/apr/10/child-rapist-fooled-judge-thinking-he-wasdisabled-jailed. The perpetrator's wife was also sentenced for perverting the course of justice. She had first assisted in the deception and then informed on her husband arguing coercive control.

21 https://www.judiciary.uk/judgments/ian-brady-mh-tribunal-240114/.
} 
type' (a longstanding diagnosis) and a 'mental illness of a psychotic nature, characterised by persistent auditory hallucinations, olfactory and somatic hallucinations and a paranoid delusional system. His paranoid delusional system prevents him from accepting the advice of the prison authorities and militates against improvement in his present environment.'22 In 2013 he sought to be transferred back to prison on the basis that he no longer satisfied the criteria under the Mental Health Act 1983 for continued hospital detention. The Tribunal observed that Brady's ability to 'hide or mask his symptoms' did create difficulties in determining a diagnosis. ${ }^{23}$ Indeed, they accepted, as did all the medical witnesses, that 'without the cooperation of the patient diagnosis is difficult'. ${ }^{24}$ Brady had contended that he had been 'method acting' in 1985 in order to obtain his transfer to the hospital, 25 and he disputed ever having had any mental disorder, and, in particular, schizophrenia. Indeed, he claimed that the doctors who had recommended his transfer in 1985 knew that he was feigning his symptoms; he claimed that his bizarre and delusional behaviour was attributable to 'Stanislavski'. ${ }^{26}$ By 2013 establishing this with any certainty was problematic, but all the medical witnesses took the view that he had been ill at the point of transfer, albeit they disagreed as to whether that illness persisted, or persisted to a sufficient degree to enable him to continue to be legally detained in hospital. The logical difficulty for Brady was that if he could claim to act ill when he was sane, then it was harder to refute clinical assessment that he was now acting sane (or masking his symptoms in the language used) when he was ill. Disorder, according to the clinicians caring for him, could persist in the absence of symptoms. Notably, the tribunal accepted that 'the lack of positive evidence of the continuation of such experiences does not preclude the presence of schizophrenia'. ${ }^{27}$ Indeed, they went on to conclude that he had a mental condition (a chronic psychotic illness) of a nature, and probably also of a degree, that made his continued detention in hospital appropriate. ${ }^{28}$ Brady died, in hospital, in 2017.

\section{B. FEAR OF MALINGERING}

The case here, that of Lord Greville Janner, also concerns unfitness to plead where an initial decision was made by the Director of Public Prosecutions (DPP) not to prosecute. The history is complex, but it is evident both in the statement made by the $\mathrm{DPP}^{29}$ and in the press coverage at the time, that the aura of potential malingering was present with respect to Janner's dementia. Janner had been

\footnotetext{
22 Para 83 judgment.

23 Para 26 judgment.

24 Para 119 judgment.

25 Para 110 judgment.

26 Para 110 judgment.

27 Para 200 judgment.

28 Para 200 judgment.

${ }^{29}$ The decision not to prosecute Lord Janner - statement from the DPP, www.leicestermercury.co.uk $9^{\text {th }}$ November 2015 (hard copy available from the author).
} 
repeatedly accused of historic child sexual abuse over a number of years involving a number of complainants, but nothing had transpired with respect to formal proceedings. In 2015, on a further review, the DPP Alison Saunders concluded that the allegations were sufficiently legally robust to have passed the Crown Prosecution Service's first test of evidential sufficiency. She stated that the cases ought to have been prosecuted much earlier. However, she also concluded that it would no longer be in the public interest to prosecute as Janner had developed severe dementia. The public interest test forms the vital second element of the DPP's criteria for prosecution. The DPP argued that if the charges were pursued Janner would be found unfit to plead; and any trial of the facts that produced positive findings would merely result in the Judge ordering a discharge. This was because Janner required full-time care for his dementia; and that care was already being provided by his family. In so doing the DPP asserted, on the basis of the four medical assessments she had seen, "Manipulation ("putting it on") is "out of the question". 30 However, the complainants invoked their right to a review of the DPP's conclusions. ${ }^{31}$ This resulted in a different assessment of the public interest test being formed by David Perry QC, a reviewer independent of the Crown Prosecution Service; and proceedings were then brought against Janner, even though David Perry shared the DPP's view that the case would need to go via the unfitness procedure. After his first appearance in the Westminster Magistrates' Court, 32 there were subsequent findings by a High Court Judge (in Janner's absence but on the basis of medical reports) that he was indeed unfit to plead; and a date was fixed for the trial of the facts to be held in April 2016.33 Lord Janner died before this took place. Whilst the critical factor in all of this was an understandable dispute about what the public interest test required in such cases, it was clear that the DPP felt it necessary to address the wider anxiety about legal malingering, even though such anxiety was manifestly absurd in his case.

\section{Vulnerability OF ASSESSMENT METHODS}

Suspicions about the susceptibility of unfitness assessments had also permeated the earlier Pinochet case. General Augusto Pinochet was arrested in 1998 in London on a European Arrest Warrant from Spain, with a view to extradition there. He spent 18 months in the UK under house arrest until the House of Lords upheld the extradition application. However, the then Home Secretary Jack Straw released Pinochet for return to Chile on medical grounds. These were a

${ }^{30} \mathrm{Ibid}$.

31 The CPS Victims' Right to Review was brought in by the former DPP, Keir Starmer QC, in 2013,

https://www.cps.gov.uk/legal-guidance/victims-right-review-scheme. Notably, it is termed a 'Victims' Right' and not a 'Complainants' Right', giving seeming pre-eminence to a complainant's narrative rather than that of the accused person.

32 https://www.bbc.co.uk/news/uk-33931860.

33 https://www.bbc.co.uk/news/uk-35027705. 
combination of physical problems and senility. On return to Chile legal proceedings continued, but the indictment was ultimately dismissed by the Supreme Court in 2002 on grounds of vascular dementia. However, in 2004 the Supreme Court further ruled that Pinochet was capable of standing trial (he had given a TV interview which cast doubt on the assessment of senility). Legal proceedings ground on thereafter, but Pinochet died in 2006 without having been convicted of any crime. ${ }^{34}$

The second illustration concerns the Guinness case. This is the example that most people will cite in discussions of legal malingering. Ernest Saunders was the chief executive of Guinness plc. He was one of four individuals convicted in 1981 of fraudulently attempting to manipulate the share price of Guinness. ${ }^{35}$ Saunders was sentenced to five years in prison but released after 10 months because of what was thought to be the early signs of dementia - in his case Alzheimer's disease. In practice, he made a full 'recovery' after release and pursued a career as a business consultant. Getting to the bottom of what diagnosis was offered in his appeal is not easy. And it is possible that his full recovery on release is consistent with a diagnosis of depression and/or memory loss brought on by stress. Indeed, the trauma associated with offending, prosecution and conviction, and subsequent punishment should not be trivialised.

It is certainly the case that the three experts did not fully agree with one another; and that the assertion of pre-senile dementia may have been accepted by the Appeal Court on the basis of its understanding of the medical evidence, without that medical evidence ever conclusively supporting such a diagnosis. ${ }^{36}$ Whatever the truth of the matter, the case lives on in the public's imagination as one where a convicted fraudster was able to 'pull the wool over the eyes of experts' (a psychiatrist and two neurologists) through an easy manipulation of the memory tests administered. ${ }^{37}$ Of course, Ernest Saunders may not have engaged in any manipulation, active or otherwise, and such tests are vulnerable to the effects of stress. Clinicians can and do get things wrong. Moreover, in these uncertain areas, clinicians will disagree with one another, and express their views with understandable hesitancy, which can all feed a fear of experts making errors. Indeed, in its (albeit draft) 2019 Guideline on Sentencing Offenders with Mental Health Conditions or Disorders the Sentencing Council stresses that whilst expert evidence should be considered, sentencers 'should not feel bound to follow expert opinion'. ${ }^{38}$ In the event, it is notable that neither medical nor legal procedures

\footnotetext{
34 See https://www.nytimes.com/2000/01/12/world/pinochet-is-ruled-unfit-for-a-trial-and-may-befreed.html.

${ }^{35}$ He was convicted of 12 counts of conspiracy to contravene section 13(1)(a)(i) of the Prevention of Fraud (Investments) Act 1958, false accounting and theft.

36 Dr Perkin, consultant neurologist to the Crown and one of three expert witnesses, maintained during the appeal that Mr Saunders was suffering from depression and not a degenerative brain disease. He reiterated his diagnosis in the June edition of the British Medical Journal in 1992 (taken from Independent 30 Dec 1994).

37 https://www.independent.co.uk/news/forget-alzheimers-saunders-1388784.html.

38 https://www.sentencingcouncil.org.uk/offences/magistrates-court/item/sentencing-offenders-withmental-health-conditions-or-disorders-for-consultation-only/ at para 9.
} 
were found wholly robust. For in 1996 the European Court of Human Rights (ECHR) concluded that Saunders' initial trial had entailed a breach of article 6 of the Convention. ${ }^{39}$

Ironically, the difficulties and nuances of this real-life judgment had been foreshadowed by what is perhaps one of the most famous real-world experiments. David Rosenhan's On being sane in insane places constitutes the final preliminary illustration of the difficulties of legal malingering. 40 Rosenhan's team of researchers presented themselves at various psychiatric hospitals in the United States claiming to hear a voice in their heads which reportedly said 'empty' 'hollow' or 'thud'. Eight gained access to 12 different hospitals. Immediately after admission the pseudo-patients stopped reporting any abnormal symptoms and behaved naturally as researchers, making notes of what they witnessed around them. It took between seven and 52 days before they were discharged; all then with a diagnosis of schizophrenia in remission'. Notably, normal behaviours by them (for example, 'writing') were interpreted as symptoms of their disorders. After the findings became known there was considerable concern in the psychiatric community that the research suggested that psychiatrists were prone to being fooled; and Rosenhan's team were invited to repeat it at one research and teaching hospital over an agreed three-month period. The assumption was that the hospital would be able to spot any subsequent pseudo-presentations. In practice, Rosenhan sent no further pseudo-patient-researchers, but the hospital identified 41 presenting 'patients' as fakes. As Rosenhan noted this false negative rate could reflect one of two factors. Either staff, in an attempt to avoid making false positive errors, overcorrected their diagnostic thresholds; making ill people, in their view, sane on the grounds of attributed malingering. Or some people who were suspected of being sane (and were malingering) were indeed sane. Psychiatric diagnosis was thus potentially prone to both false positive and false negative errors; similar errors in the area of risk prediction by clinicians would now be widely recognized. ${ }^{41}$ One might have asserted that the Rosenhan study sits as an ancient shipwreck on the record of objective psychiatric diagnosis - a mere aberration - but 30 years later Lauren Slater controversially claimed to have presented herself at psychiatric hospitals with the single symptom of hearing a voice saying 'thud'. ${ }^{42}$ Unsurprisingly, hospitalization did not occur in that era, but

\footnotetext{
39 Saunders $v$ UK 17th December 1996 (Application no 19187/91), by a majority of 16-4. Saunders was awarded $f 75,000$ costs and expenses. But the violation of article $6-$ namely that the prosecution had resorted to evidence obtained through coercion or oppression - was held to be sufficiently justly satisfied by the court's finding of a violation. Hence, there was no award for non-pecuniary damages.

40 Rosenhan D (1971) 'On Being Sane in Insane Places’ Science 179: 250-58.

41 Szmukler G (2003) 'Risk assessment: 'numbers' and 'values” Psychiatric Bulletin 27: 205-207; Szmukler J and Rose N (2013) 'Risk Assessment in Mental Health Care: Values and Costs' Behavioural Sciences and the Law 31: 125-140.

42 Slater L (2004) Opening Skinner's Box: Great Psychological Experiments of the 20 ${ }^{\text {th }}$ Century London: Bloomsbury Publishing. Slater has described her work as 'anecdote, not systematic research, and certainly not a "replication" of Rosenhan's study' (https://upclosed.com/people/lauren-slater/) so the work is
} 
she was given a diagnosis of depression with psychotic features and prescribed numerous anti-psychotics and anti-depressants. Thus, the locus of care may have shifted into the community in the intervening years, but seemingly not the potential susceptibility of psychiatry to the false positive phenomenon. Both publications play to anxieties about the reliability and validity of clinical assessment and its vulnerability to patients' reports of their own symptoms.

It should also be stressed that diagnosis is not a 'one way' street. Patients are diagnosed partly on the basis of their objective symptoms, partly on the basis of what they report to clinicians and partly on the basis of the clinician's experience of all the relevant contextual factors. As with Brady above, a refusal to engage will make the clinician's task highly problematic. However, the process of reporting can also be subject to manipulation by the alleged disordered individual when they deem it to their advantage so to do. The illustration here derives from the Breivik case. Anders Behring Breivik killed 77 people, 69 of them by shooting on the island of Utoya in Norway, but a further 8 people in Oslo in a prior explosion. Breivik was initially diagnosed with a psychotic disorder and would have been held legally unaccountable - insane - under Norwegian law on the basis of this diagnosis. However, two further clinicians diagnosed him six months later with a severe narcissistic personality disorder, combined with pseudologia fantastica (pathological lying). These second two clinicians found him psychotic neither during their interviews nor at the time of the offences. He was thus legally accountable for what he had done. Melle argues that the main difference between the two evaluations was that, nine months after the attacks, Breivik 'appeared more open to alternative explanations concerning his own role, which made the reality testing regarding his grandiose notions appear less impaired'. ${ }^{43}$ As an offender aware of the implications of the first diagnosis, Breivik's responses to the second evaluation may well have contributed to the diagnosis, since he may have desired to portray his actions as rational and political, rather than deriving from a deranged mind. Thus, the clinical evaluation of offenders is vulnerable to alternative assessments by different clinicians, alternative assessments over time, re-interpretation of the assessments by the courts, and potential manipulation of the assessments by the accused.

None of this so far takes account of the further difficulty of the extent to which fundamentally honest individuals can convince themselves of their own illjudged narratives. Or fail to recognise their own disabilities whether attributable to socio-cultural factors, the stigma associated with mental disability or many of a number of other potentially contributory factors. But whatever the cause, the confidence of an individual in their own narrative and the practised coherence of it can make assessments by others even more difficult.

noted here with caution. Her previous book Lying: A Metaphorical Memoir (2000) New York: Random House, narrates a life marked by a disease she may or may not have, namely epilepsy.

${ }^{43}$ See fn 1 at 19. 
The Blackman case is illustrative. ${ }^{44}$ Alexander Blackman was an Acting Colour Sergeant in the Royal Marines when he shot and killed an already badly wounded insurgent in Afghanistan in 2011. He was tried on the charge of murder before a court martial and convicted. His defence was that the insurgent was already dead when he shot him. Video evidence of the incident set out in detail what had happened. For the purposes of sentencing a psychiatric report was prepared in 2013; it noted that Blackman may have been suffering from an undetected combat stress disorder, which would be an extenuating factor for the purposes of punishment. On appealing his life sentence with a ten year tariff the Court Martial Appeal Court reduced the tariff to 8 years. Subsequently, the Criminal Cases Review Commission referred the case back to the court on the grounds of both conviction and sentence. Further psychiatric evidence was produced from two more psychiatrists showing that Blackman was suffering from an adjustment disorder at the time of both the killing and the court martial. Such evidence would potentially make available the partial defence of diminished responsibility.

The prosecution accepted the evidence of the adjustment disorder, but contested whether the disorder might have or had substantially impaired Blackman's responsibility for the killing. Thus, having the disorder was regarded as a necessary but not necessarily sufficient basis for reducing the conviction for murder to one of manslaughter. Notably, whilst the video evidence starkly documented what happened at the time, ${ }^{45}$ the relevant issue was Blackman's mental state and its impact on his rationality and self-control; and capturing this was arguably beyond the capacity of video evidence.

Adjustment disorders were recognised under ICD 10.46 The three psychiatrists agreed his was of moderate severity. The symptoms can be masked and not apparent to others, or to the person suffering from it. Those with such disorders can plan and act with apparent rationality; but the disorder is capable of substantially impairing the capacity to form a rational judgment or exercise selfcontrol. Failure to seek a psychiatric report prior to trial was attributed to Blackman's non-recognition of his psychiatric state; and because he would not want to rely on a psychiatric defence because of the stigma perceived to attach to it, perceived weakness and the likely end of his career.

Two of the psychiatrists concluded on the basis of their diagnosis of the adjustment disorder (derived from their interviews with Blackman), together with factors relating, for example, to the particular conditions in which Blackman was functioning, ${ }^{47}$ that his responsibility was substantially impaired. The third, Dr

\footnotetext{
${ }^{44}$ https://www.judiciary.uk/wp-content/uploads/2017/03/r-v-blackman-judgment-150317.pdf.

${ }^{45}$ See judgment para 22 (xvi) where it is recoded that Blackman said to his colleagues, after he shot the insurgent: 'Obviously this doesn't go anywhere, fellas. I've just broke the Geneva Convention'.

${ }^{46}$ The International Classification of Diseases, $10^{\text {th }}$ Edition, F43.2 (WHO). This has now been updated in ICD

11 (2018).

${ }^{47}$ See para 39 judgment.
} 
Joseph, reached that conclusion 'on balance'. Professor Greenberg gave evidence that $20-25 \%$ of combat troops deployed to Iraq and Afghanistan at some point suffered from a mental health difficulty and that about one third of those diagnosed had an adjustment disorder. It might seem paradoxical that troops who are trained to withstand stress seem so vulnerable to it; but the adequacy of the training and the severity of the stresses to which troops are exposed may simply overwhelm the effects of any training possible.

In the event, the Court of Appeal accepted the psychiatric evidence, observing how unfortunate it was that contemporaneous assessments of those charged with murder were not routinely obtained, despite exhortations from the courts that this should be the practice.48 And that this was even more so where there was a responsibility placed on the armed forces in respect of the mental health and welfare of troops. Having accepted that the evidence could have raised a doubt as to guilt in the minds of the Court Martial, they quashed the conviction for murder as unsafe. Having done that they then went on to review the evidence for themselves as to whether the impairment was sufficient for them to substitute a verdict of diminished responsibility manslaughter - an avenue open to them given Blackman's new admission that he had intended to kill the insurgent. ${ }^{49}$ And they concluded on the balance of probabilities that they were so satisfied.

This brief synopsis cannot do justice to the Court's reasoning. However, they concluded that it was possible to have an adjustment disorder which did not affect one's capacity to plan, but did affect the ability to form a rational judgment about adhering to moral standards or thinking through the consequences of one's actions. This was consistent with, for example, the psychiatric evidence in the earlier case of Brennan. ${ }^{50}$ They also concluded that Blackman's decision to kill was probably impulsive and that the adjustment disorder had substantially affected his ability to exercise self-control.

Four aspects are notable with respect to issues of uncertainty. First, the court only had to be satisfied on a balance of probabilities: this is entirely appropriate since psychiatric evidence would struggle to achieve the standards necessary for a beyond reasonable doubt verdict. Second, disorders can be masked from both sufferers and contemporaneous observers (albeit in Blackman's case there was non-psychiatric evidence that he had been observably affected ${ }^{51}$ ). Third, resistance to psychiatric explanations and the attributed stigma perceived to be associated with them can result in legal proceedings being unnecessarily drawn out. ${ }^{52}$ Finally, trying to assess the partial role of mental disorder in culpability is difficult enough; tackling this many years after the incident in question can only result in

\footnotetext{
48 See para 79 judgment.

49 See para 10 judgment.

${ }^{50} \mathrm{R} v$ Brennan [2014] EWCA Crim 2387.

51 See para 105 of the judgment in Blackman above.

52 Notably, Blackman has subsequently written a book about his experiences in which he says he was unaware at the time that he was suffering; see https://www.theguardian.com/uk-news/2019/apr/18/iwasnt-aware-i-was-suffering-marine-a-talks-about-troops-mental-health and Blackman A (2019) Marine A: My toughest battle: The truth about the murder conviction London: Mirror Books.
} 
uncertainty. Understandably, and rightly so, uncertainty favours the defence not the prosecution.

So far legal malingering has appeared in a number of guises: actual, feared, claimed, attributed, mediated and resisted. That it is possible to illustrate these types however gives no sense as to their frequency. If comparatively infrequent, the concern the criminal justice system has about being exploited would be misplaced. If relatively frequent it raises questions about how good the system is in picking up such potential corruption of its processes. But both bear on the issue of trust in the system; for without trust the criminal justice system is vulnerable, since the system is reliant on the willing participation of witnesses, victims and the accused.

\section{THE PROBLEMATIC CONTEXT}

The focus of the discussion thus far, on malingering in its numerous guises, needs to be broadened out. It has already been shown, through the Blackman case, that individuals can be highly resistant to a psychiatric explanation of their behaviour. And resistant to a point that is profoundly damaging to them. But this resistance to psychiatric or psychological explanations has a parallel in the work of Suzanne O'Sullivan. O'Sullivan is an eminent neurologist and she has demonstrated in her book Is It All in Your Head? True Stories of Imaginary Illness how psychosomatic illnesses can be very real to the sufferer. ${ }^{53}$ Medically unexplained symptoms do not mean that the sufferer is making them up; just that medicine has not yet found the way to document and explain the mind's experience of bodily sensations. What seemingly lies behind these psychosomatic illnesses (which are not the same as malingering as neither patient nor clinician is in any doubt about the distress and suffering involved) is some form of psychological or psychiatric stress-related explanation. Yet, as O'Sullivan documents, such patients are remarkably resistant to the notion of giving up on a physical explanation for their suffering and accepting psychological or psychiatric treatment. ${ }^{54}$ The stigma associated with having a condition such as these, rather than a physical illness, is evident. It can also contribute to delay in diagnosis, an issue which haunts the criminal justice system.

In the offending context, such resistance can also be documented; alongside a preparedness to embrace such explanations in other individuals. ${ }^{5}$ As noted above, the extent to which individuals can become committed to their own narratives is

\footnotetext{
53 See fn 12.

54 See fn 12 on chronic fatigue syndrome or myalgic encephalomyelitis.

55 See, for example, https://www.theguardian.com/society/2019/may/23/birmingham-man-jailed-forstealing-150-can-of-beer. The causes of crime are multifactorial; explaining crime is all too frequently reductionist.
} 
potentially a confounding factor for those clinicians who have to assess the validity of whatever they are being told by the individual they are assessing.

The final case returns to the issue of unfitness to plead and illustrates not a resistance to a psychiatric diagnosis but a possible embrace of it. Shrien Dewani was accused in 2010 of offering money to have his wife Anni murdered whilst they were on their honeymoon in Cape Town. The Dewanis had been on a tour, by taxi, of the Gugulethu township where Shrien was robbed and pulled from the taxi. Anni's body was found the following morning in the same taxi, having died from a single gunshot wound in what appeared to be a robbery gone tragically wrong.

After the death three local men were arrested and charged. Dewani returned to the UK with his wife's body. At some point there appears to have been a plea bargain in which the local men changed their admissions and implicated Dewani. Back in the UK he was accused of conspiracy to murder, and subsequently extradited back to South Africa. At his trial he was acquitted by the judge of all charges at the close of the prosecution case. ${ }^{56}$ The judge observed

To summarise, Mr. Tongo, who was the only witness who could link the accused to this conspiracy, gave evidence to the court which is so improbable and contains so many mistakes, lies and inconsistencies that one simply cannot know where the lies end and the truth begins. I accept that at this stage of the proceedings the credibility of a witness plays a limited role. But, in my view, the evidence of these witnesses is so replete with fundamental contradictions on the key components of the State case that I can all but ignore it. In making this finding, I take into account that all three witnesses, Mr. Tongo, Mr. Mbolombo and Mr. Qwabe are intelligent people, and therefore more than capable of attempting to twist their version to implicate the accused. ${ }^{57}$

The case understandably gained some notoriety in the four-year interval between the proceedings for extradition and Dewani's exoneration in South Africa. The inherent improbability of a man arranging to have his wife murdered on their honeymoon was countered by suggestions that Dewani was gay, and accordingly had some kind of motive. In fact, Dewani admitted at the start of his trial that he was bisexual; the stress of knowing this but seemingly not admitting it publicly during the significant period during which the extradition was fought cannot have been easy. In any event, knowing that he had been wrongly accused of the most serious of crimes and might be convicted nonetheless, combined with the trauma of losing his wife in these horrific circumstances would, one might think, be enough to bring about mental health problems in any accused person. But, of course, during that time before the conspirators' false allegations had been tested

${ }^{56}$ S v Dewani (CC15/2014) [2014] ZAWCHC 188 (8 December 2014).

57 Para 24.4 judgment. 
and found wanting, it remained a possibility that Dewani had indeed been involved in the plot. Even had that been the case, the trauma of the plot's realization would still have been present together with the possibility that he would face a life sentence if convicted in South Africa, and could equally have contributed to his depression and post-traumatic stress disorder. Finally, a man who had cold-bloodedly planned his new wife's murder, might think nothing of attempting to feign such mental disorder. The potential causation of the mental disorder was thus contestable.

As one can imagine, the extradition case attracted significant media interest. A report during the hearing by the Telegraph (not a tabloid paper) encapsulated the toxic mix of innuendo, psychiatric difficulties and contested assessments. ${ }^{58} \mathrm{His}$ defence team had argued that not only was he unfit to attend the extradition appeal - he was at that time detained under the Mental Health Act 1983 - but also that he would be unfit to plead under English law, and hence unfit to be sent back to South Africa. Interestingly, Senior District Judge Riddle, the Chief Magistrate, had earlier ruled that the evidence showed that Dewani would receive appropriate mental health care in South Africa and had sent the case to the Secretary of State, who ordered the extradition. This decision was subject to appeal to the High Court in 2012 where it was argued, amongst other matters, that Dewani's risk of suicide attendant to his mental condition, meant that he should not be extradited. ${ }^{59}$ In the event, at a further hearing in 2014 the High Court upheld the Magistrate's ruling in favour of extradition, having been given assurances by the South African Government that there would be a limit on how long he could be detained prior to his trial there. ${ }^{60}$ The Court, headed by the Lord Chief Justice, held that it would not be 'unjust and oppressive' under s.91 of the Extradition Act 2003 to extradite him in the light of that undertaking. ${ }^{61}$

The chronology of the case is complex, but it is noteworthy that the two psychiatrists who gave evidence to the Chief Magistrate disagreed as to the severity of Dewani's post-traumatic stress disorder (Professor Eastman, for Dewani, arguing it was severe, and Dr Cumming for the South African Government that it was moderate/severe). His depressive disorder was considered moderate to severe and there was a real risk of self-harm and suicide. They both agreed he was unfit to plead under English law. Neither expected a full recovery from his disorders, any improvement was likely to be extremely slow and the end point was uncertain.' ${ }^{2}$ Dr Cumming took the view that extradition proceedings were a factor

\footnotetext{
58 https://www.telegraph.co.uk/news/uknews/crime/8646519/Shrien-Dewani-case-unfit-suspectworks-out-court-told.html.

59 https://www.judiciary.uk/wp-content/uploads/JCO/Documents/Judgments/gov-south-africa-vdewani-judgment.pdf.

60 https://www.theguardian.com/world/2014/jan/31/shrien-dewani-high-court-extradition-south-africa.

61 https://www.judiciary.uk/wp-content/uploads/JCO/Documents/Judgments/govt-republic-southafrica-v-dewani2-finaljudgment.pdf.

622014 judgment at para 10.
} 
in helping to maintain the appellant's illness; ${ }^{63}$ Professor Eastman favoured delay and argued that the prognosis was very poor if the appellant went to South Africa and did not improve. He thought there was a risk of him becoming 'chronically severely ill and chronically unfit to plead'. ${ }^{64}$ The Chief Magistrate noted that the arguments were finely balanced; in effect, not extraditing him now might miss an opportunity for recovery; and equally, extraditing him may set back his recovery. ${ }^{65}$

Notably, the second High Court decision (in which the Lord Chief Justice presided) concluded that provided there was not a real prospect that the unfitness would be permanent, current unfitness was not a bar to extradition for the purposes of prosecution in another country; ${ }^{66}$ albeit there needed to be an intense focus on the facts for which the accused person was being extradited. And since Dewani's mental health conditions were neither incurable nor permanent, and the South African legal procedures were fair to those alleged to be unfit, the Court rejected the submission that the appellant was not 'an accused person' under s.70(4) of the 2003 Act and could, potentially, be extradited. They went on to hold that extradition would not be unjust given the South African government's assurances as to timing above. So it was not unjust per se to extradite an unfit person. But the Court wanted a further assurance that if Dewani remained unfit at the point of 'trial', having been found unfit by the South African Court, that he should be free to return to the UK before the court embarked on the process of determining (under the Criminal Procedure Act 1977) whether he 'did the act'.67 This would obviate any long term detention in South Africa justified by unfitness.

Since a conventional trial did go ahead, it must have been the case that once in South Africa Dewani was found fit to plead. In that conventional trial he was acquitted and returned to the UK. The press noted at that time that the entrance to his house had been vandalised with white paint. ${ }^{68}$ By 2017 the press were also reporting his business as making significant profits. ${ }^{69}$ The judge in the case in South Africa was subject to a complaint of bias against the prosecution in the handling of the trial. ${ }^{70}$ The notion that court proceedings bring resolution to uncertainty seems tenuous. Is the taint of an underlying suspicion of malingering as hard to shift as the 'no smoke without fire' response to criminal acquittals?

With respect to the argument here the key issue is how an assessment of unfitness might have delayed or prevented extradition leading to trial altogether. Here the contrary assessments of the psychiatrists were telling; assessing current unfitness is one matter - but being asked to make a prediction as to how that unfitness might develop in the context of extradition to another jurisdiction where

\footnotetext{
63 Para 12 judgment.

64 Para 11 judgment.

65 Para 13 judgment.

66 Para 37 judgment.

67 Para 60 judgment.

68 https://www.news24.com/World/News/Dewanis-UK-home-vandalised-20141211.

${ }^{69}$ https://www.dailystar.co.uk/news/latest-news/626595/Shrien-Dewani-honeymoon-murder-firmmoney-Bristol.

70 https://www.news24.com/SouthAfrica/News/Complaint-lodged-against-Judge-Traverso-20150122.
} 
less familiar arrangements for detention, clinical care and trial prevail, is quite another. So it is perhaps not surprising when asked to make assessments that included both backward and forward looking elements (how might the unfitness change if extradited) that the clinicians did not fully agree.

Resistance to the role that psychiatric diagnosis can play in alleviating criminal culpability, if not wholly absolving an offender from responsibility, can also be seen in the progressive decline in the verdict of diminished responsibility manslaughter. The work of Ronnie Mackay and his colleagues is critical to understanding this. ${ }^{71}$ Again these issues are not easy to unpick, but it would seem that there is still resistance in the courts to accepting the evidence of psychiatrists (see eg $R v$ Brennan $^{72}$ ) and a decline in the number of successful diminished responsibility contested pleas following the introduction of the amended criteria for diminished responsibility via s.52 of the Coroners and Justice Act 2009. Section 2 of the Homicide Act 1957 now requires a defendant to demonstrate (on a balance of probabilities) that they had an abnormality of mental functioning caused by a recognised medical condition, which provides an explanation for the defendant's acts or omissions in being party to the killing and which substantially impaired his/her mental ability to either: a) understand the nature of their conduct or b) form a rational judgment or c) exercise self-control. ${ }^{73}$ Notably, an abnormality of mental functioning provides an explanation for the defendant's conduct if it causes, or is a significant contributory factor in causing the defendant to carry out that conduct. ${ }^{74}$ Requiring the abnormality of mental functioning to have a causative role in the offence necessarily and problematically involves psychiatrists in this stage of any defence. ${ }^{75}$

Mackay and Mitchell note, with respect to the introduction of the new plea, that there were 'more contested pleas with convictions for murder being returned in $34.4 \%$ of these cases compared to a murder conviction rate of $14 \%$ under the old plea' ${ }^{76}$ The authors conclude that if there has been this unplanned increase in murder convictions 'then it is important to discover the reasons for this'. ${ }^{77}$

This potentially worrying trend is likely to be enhanced by the Supreme Court's ruling in the case of Golds, ${ }^{78}$ which concerned diminished responsibility. The ruling clarified first that the meaning of the word 'substantial' as an ordinary English word should be left to the jury to give it their commonly understood meaning; and second, in that minority of cases where a direction was needed the

\footnotetext{
${ }^{71}$ Mackay R (2018) 'The impairment factors in the new diminished responsibility plea' Criminal Law Review 457-466; Mackay R and Mitchell B (2017) 'The new diminished responsibility plea in operation: some initial findings' Criminal Law Review 18-35.

${ }^{72} \mathrm{R} v$ Brennan [2014] EWCA Crim 2387.

73 S.2 Homicide Act 1957.

74 S.2 (1B) Homicide Act 1957.

75 Peay J (2016) 'Responsibility, Culpability and the Sentencing of Mentally Disordered Offenders: Objectives in Conflict' Criminal Law Review 152-164.

76 Mackay and Mitchell fn 71 above at 35.

77 Ibid.

${ }^{78} \mathrm{R} v$ Golds (2016) UKSC 61.
} 
court should tell the jury that substantial meant something 'important or weighty' and not something merely present, that is of substance. Whilst the judgment will hopefully be helpful to psychiatrists who can take cognizance of it when preparing their reports, it is hard to see how leaving the definition to the jury without the additional limb will protect them from their own preconceptions in this very tricky area. And those preconceptions will, of course, be under the radar where the jury do not seek further clarification from the Judge, and the Judge does not see fit to give such clarification unasked.

\section{THE PARADOXICAL CONTEXT}

Despite the easy examples given above, the real issues in this area paradoxically concern the under-diagnosis of unfitness ${ }^{79}$ and the tendency to over-attribute the causes of crime to mental disorder. ${ }^{80}$

First, under-diagnosis. This is important as it will result in defendants with disabilities being unable to meet the demands of a criminal trial, and potentially being convicted unfairly. So the problem is not accused individuals taking advantage of the system through malingering, but needy individuals being taken advantage of by a system that should be protecting them. The anxiety that too many unfit defendants are unfairly exposed to the rigours of the criminal justice process lies at the heart of the Law Commission's proposals for reform of unfitness to plead. ${ }^{81}$ Notably, anxieties about malingering do not feature, so it is curious that the DPP in the Janner case ever thought it appropriate to mention this. Perhaps she was cognizant of how her decision might play in the press. Suffice it to say here the numbers of offenders in the prison population, both in England and Wales, and internationally, with various forms of mental disorder, many with the most disabling disorders, should concern any system that is interested in fair processes for the assessment of guilt. ${ }^{82}$ So the Law Commission's focus was entirely appropriate. It is, of course, the case that the overwhelming proportion of those imprisoned have pleaded guilty to their offences, but this is no adequate response to the notion that the process may have been unfair. Indeed, the Law Commission was alert to this problem and made two relevant recommendations. First, to place a much greater emphasis on ensuring that support is given to enable defendants to engage meaningfully with trial processes, which would both help to avoid unnecessary unfitness pleas and encourage those

\footnotetext{
${ }^{79}$ Law Commission (2016) Unfitness to Plead Report: Volume 1 Report; Volume 2 Draft Legislation, http://www.lawcom.gov.uk/project/unfitness-to-plead/.

${ }^{80}$ Bean P (2008) Madness and Crime Cullompton, Devon: Willan Publishing; Peay J (2011) Mental Health and Crime Oxon: Routledge.

$81 \mathrm{http}: / /$ www.lawcom.gov.uk/project/unfitness-to-plead/.

${ }^{82}$ Fazel S and Danesh J (2002) 'Serious mental disorder in 23000 prisoners: a systematic review of 62 surveys' Lancet 359: 545-5.
} 
who are not guilty to resist the pressure to plead guilty. ${ }^{83}$ Second, they recommended a route to enabling guilty parties to plead to their offences, even when unfit, that would be subject to scrutiny and take account of their disabilities. A test that would better identify those who can fairly be exposed to the trial process, and those who ought properly to be protected from it via an unfitness to plead route, has been under development. ${ }^{84}$ Ultimately, this test should be able better to distinguish those who are genuinely unfit, from those who are fit, whilst obviating any residual concern about malingering. But, in essence, concerns about malingering in the unfitness process are overplayed: they are largely but not exclusively imaginary.

The second paradox is the over-attribution of offending to mental disorder. This invites illness-based explanations of criminal behaviour; but it also contributes to the negative stigma around mental disability. The arguments about the paradox of over-attribution are more complex. To start, in individual cases the attribution of the cause of a crime to mental disorder may be justified, but the process of so doing, particularly where a disability is hitherto unacknowledged or insufficiently acknowledged, is a precarious task. A sympathetic approach to the experience and reality of mental disorder, and a compassionate approach by the criminal justice system, should not supplant the normal 'testing' processes. So the enthusiasm of a sufferer to point towards an aspect of their make-up as somehow accounting for their aberrant behaviour needs further exploration. Moreover, it needs careful consideration in the light of evidence that even amongst those with mental disorder, mental disorder is not the prime driver of crime.

It is also notable that there has been an extensive and sometimes unedifying history associated with this topic; with a longstanding presumption that somehow mental disorder made individuals more likely to commit crime. Unpacking the reality of this has resulted in a number of conclusions; not the least of which is that some mental disorders are more likely to make sufferers less likely to engage in crime, because they reduce the motivations and opportunities so to do. For example, chronic conditions, like long-term schizophrenia, where the negative symptomatology outweighs the positive symptomatology, can result in social withdrawal, thereby reducing the opportunities to commit some kinds of crime. Equally, it is evident that some conditions do raise the risk of sufferers engaging in violent crime. For example, those with bipolar disorder have an increased risk for violent crime, albeit most of the excess is associated with comorbidity for substance abuse. ${ }^{85}$ Interestingly, in this major study involving 3,743 individuals

83 Peay J and Player E (2018) 'Pleading Guilty: Why Vulnerability Matters' Modern Law Review 81(6): 929957.

84 Brown P, Stahl D, Appiah-Kusi E, Brewer R, Watts M, Peay J and Blackwood N (2018) 'Fitness to Plead: development and validation of a standardised assessment instrument' PLOS ONE, https://journals.plos.org/plosone/article?id=10.1371/journal.pone.0194332.

${ }^{85}$ Fazel S, Lichtenstein P, Grann M, Goodwin G and Langström N (2010) 'Bipolar Disorder and Violent Crime: New Evidence From Population-Based Longitudinal Studies and Systematic Review' Arch Gen Psychiatry 67(9): 931-938. 
with bipolar disorder, no differences were found in rates of violent crime by clinical subgroups (manic vs depressive individuals or psychotic vs nonpsychotic). And, as interestingly, the unaffected siblings of those with bipolar disorder also had an increased risk for violent crime. As the authors observe, 'This finding further weakens the relationship between bipolar disorder per se and violent crime and highlights the contribution of genetic or early environmental factors in families with bipolar disorder'. 86

Moreover, contemporaneous studies that have looked at the causative role of mental disorder in those with mental disorder who commit crime, have shown that in only a small percentage of offenders did the mental disorder play an active role. For the vast bulk of arrested offenders their offences were by inference caused, insofar as these things are ever possible to ascertain, by the same factors as motivate offenders without mental disorder. ${ }^{87}$

The logical consequence of this would seem to be that if we over-value the causative role of mental disorder in crime, we ought to treat with some caution any assertion, by either an alleged offender or those assessing them, that the crime arose out of the disorder, whether that disorder pre-existed as a diagnosis, or only came to light as a result of the offending. That is not to say that crime and mental disorder are unrelated. But it is self-evident that if you take two widely occurring phenomena, you will find co-occurrences in the same individual. Indeed, some $90 \%$ of our prison population are thought to have one of five diagnosable conditions. ${ }^{88}$ However, this does not mean that the disorder caused the offending, any more than the crime and punishment caused the disorder (albeit in some it will have done, for example depression after apprehension). In this context, anxieties about the possibility of malingering, or of the exaggeration of symptoms, may be well placed. Albeit it is perhaps unsurprising that any such anxieties may be unlikely to surface in a process that in cases of doubt rightly prizes compassion above punishment. But that is not to assert that the more minimal causal role that mental disorder has in offending should lead the courts to underestimate the mitigatory role that mental disorder should play when assessing culpability for the purposes of punishment.

Finally, in some individuals there will be a causative relationship and they should arguably rightly be relieved of criminal responsibility for the offending through the vehicle of an insanity plea. Reported cases of not guilty by reason of insanity often involve extreme forms of criminal offending: as a result, they attract maximum publicity and in so doing possibly act as an accelerant to beliefs about the relationship between mental disorder and crime.

\footnotetext{
${ }^{86} \mathrm{Ibid}$ at $935-936$.

87 Junginger J, Claypoole K, Laygo R and Cristiani A (2006) 'Effects of serious mental illness and substance use on criminal offense' Psychiatric Services 57: 879-882; Peterson J, Skeem J, Kennealy P, Bray B and Zvonkovic A (2014) 'How often and how consistently do symptoms directly precede criminal behavior among offenders with mental illness?' Law and Human Behavior 38(5): 439-449.

88 Singleton N, Meltzer H and Gatward R (1998) Psychiatric morbidity among prisoners in England and Wales Office for National Statistics, London: The Stationery Office.
} 


\section{CONCLUSIONS}

This paper started with reference to the 2017 Canadian Supreme Court case of Saadati v. Moorhead. That case held that mental injury did not need to be proved by reference to a recognised psychiatric condition evidenced by psychiatrists and that the court's findings of fact, based on the testimony of the relatives and friends of the complainant that he was 'a changed man', were sufficient for the purposes of damages. Of course, a high threshold had to be passed to satisfy a claim in negligence; and psychiatric expertise could help with that task. Fundamentally though, the court was interested in symptoms and not diagnoses; and symptoms were observable by the non-clinically qualified. As they observed at para 22 concerns about feigning or symptom exaggeration 'should be resolved by "a vigorous search for the truth, not the abdication of judicial responsibility" (Linden and Feldthusen, at p. 449)';89 thus questions of fact should be resolved by the good sense of triers of fact. ${ }^{90}$

In England and Wales the courts have, with respect to some criminal issues, drifted in the opposite direction and decried the idea that lay jurors could supplant unchallenged psychiatric testimony with their common-sense understandings of evidence of planned and motivated behaviour. ${ }^{91}$ The complexities and confusions that permeate cases involving psychiatric testimony have been further illustrated by the recent decision in the Sally Challen case; here diminished responsibility was placed into the added context of coercive control. ${ }^{92}$ Contemporary psychiatric evidence of depression in Challen's original trial was seemingly insufficiently powerful to persuade a jury to return a verdict of diminished responsibility manslaughter, even though extensive complaints had been made by Challen of coercive control at the time. Some 9 years later fresh psychiatric evidence was sufficient to enable the Court of Appeal to quash the conviction for murder and order a retrial; yet ultimately further jury involvement was avoided as the CPS and a judge were persuaded to accept a plea of manslaughter without retrial. Whilst much was made by both the family and legal team for Sally Challen of the importance of the context of coercive control, the Court of Appeal did not hear the evidence on that issue from an available expert in the field; mirroring its earlier rejection of grounds of appeal based on evidence of learnt helplessness in the Ahluwalia case..$^{93}$ Indeed, in the Ahluwalia case the conviction for murder was also quashed on grounds of psychiatric evidence of diminished responsibility, and a

\footnotetext{
${ }^{89}$ Linden A and Feldthusen B (2015) Canadian Tort Law, 10th ed Toronto: LexisNexis.

${ }^{90}$ In both civil negligence claims and issues of diminished responsibility a balance of probabilities standard applies which is more tolerant of uncertainty.

91 See Brennan fn 50 above.

${ }^{92} \mathrm{R} v$ Georgina Sarah Anne Louise Challen [2019] EWCA Crim 916. Interestingly, there seems to have been a shift from learnt helplessness, where there is a focus on the abused person (see $\mathrm{R} v$ Kiranjit Abluwalia [1992] EWCA Crim 1) to coercive control, where there is a focus on the perpetrator of the abuse. This has seemingly not been explored.

$93 \mathrm{R} v$ Kiranjit Abluwalia [1992] EWCA Crim 1.
} 
retrial ordered. In the Challen case it was the psychiatric evidence by Dr Gwen Adshead of Challen's two mental disorders of borderline personality disorder and a severe mood disorder, probably bipolar affective disorder, that was determinative. The press coverage of the decision focussed almost exclusively on the issue of coercive control, with the case being described as a landmark case for victims of coercive control. ${ }^{94}$ It cannot be an understatement to say that trust in experts is in flux..$^{5}$

Making sense of this is difficult. The purpose of this paper has been primarily to raise awareness and ask some questions. Drawing in an ad hoc way on individual cases is not a comfortable place to be. But doing systematic research would be equally problematic. One argument would be that it would be better not to worry and just let the court's good sense resolve these cases as issues of fact on a case by case basis. But this would be to ignore the pernicious effects of the context of suspiciousness that may pervade these cases; and a suspiciousness that can be amplified by media involvement. Will greater openness about the difficulties lead to a greater trust in experts? Who knows?

But what should be stressed is the sense that everyone knows of a case where malingering has seemingly occurred, albeit these are rarely fully documented. Even judges, when faced with the possibility of adverse criminal proceedings, can allegedly feign disorder. ${ }^{96}$ The fear of malingering that can pervade these cases has to contend with the compassionate responses that mental ill health evokes; and rightly so. Yet symptoms of mental ill health can go unrecognised by sufferer and observer alike. Clinicians play a valuable role in unmasking these unseen phenomena; but they can also act as the midwives of manufactured or exaggerated symptoms. Theirs is an unenviable task; and particularly unenviable when called on to justify their conclusions in court.

\footnotetext{
${ }^{94}$ https://www.theguardian.com/uk-news/2019/jun/07/sally-challen-will-not-face-retrial-for-killinghusband?CMP=share_btn_link.

${ }^{95}$ See Davies (2018) fn 14 above.

${ }^{96}$ See Robertson G (2018) Rather his own man: in court with tyrants, tarts and troublemakers London: Biteback Publishing at fn 26.
} 